\title{
FACILIDADES E DIFICULDADES DA FAMÍLIA NO CUIDADO À CRIANÇA COM PARALISIA CEREBRAL
}

\author{
Meryeli Santos de Araújo DANTAS ${ }^{a}$, Jaqueline Fernandes PONTES ${ }^{\mathrm{b}}$, \\ Wesley Dantas de ASSIS ${ }^{c}$, Neusa COLLET ${ }^{\mathrm{d}}$
}

\section{RESUMO}

Pesquisa qualitativa, exploratória, descritiva, que objetivou apreender as facilidades e as dificuldades da família no cuidado às crianças com paralisia cerebral. Os dados foram coletados com sete famílias, entre março e abril de 2009 , por meio de entrevista semiestruturada. A análise seguiu os princípios da interpretação temática. As dificuldades são mais evidenciadas que as facilidades e trazem repercussões nas atividades de vida diária. Lidar com convulsões de difícil controle, espasticidade, alterações de tônus postural, presença de reflexos primitivos implicam na complexidade em tarefas simples, como alimentação, banho, locomoção, pois as crianças ficam, cada dia, mais dependentes dos cuidadores. Com o tempo, as dificuldades cedem lugar à rotina e à adaptação à vida diária da criança. Estreitar relações com a família, melhorando o vínculo e desenvolvendo ações de qualidade e integrais, promovem o bemestar da família/criança com paralisia cerebral.

Descritores: Paralisia cerebral. Família. Cuidado da criança.

\section{RESUMEN}

Investigación cualitativa, exploratoria-descriptiva que objetivó comprender las facilidades dificultades de la familia en el cuidado a los niños con parálisis cerebral. Los datos fueron recolectados con siete familias, entre marzo y abril del 2009, por medio de entrevista semiestructurada. El análisis siguió los principios de interpretación temática. Las dificultades son más evidenciadas que las facilidades y traen repercusiones en las actividades de la vida diaria. Lidiar con convulsiones de difícil control, espasticidad, alteraciones de tono postural, presencia de reflejos primitivos implica en la complejidad en tareas simples como alimentación, baño, locomoción, pues los niños se vuelven cada día más dependientes de los cuidadores. Con el tiempo las dificultades ceden lugar a la rutina y adaptación a la vida diaria de los niños. Estrechar relaciones con la familia, mejorando el vínculo y desarrollando acciones de calidad e integrales, promueven el bienestar de la familia/niño con parálisis cerebral.

Descriptores: Parálisis cerebral. Familia. Cuidado del niño.

Título: Dificultades y facilidades de la familia en el cuidado a los niños con parálisis cerebral.

\section{ABSTRACT}

This is a qualitative research and exploratory-descriptive study aimed at finding out the family's abilities and difficulties in caring for children with cerebral palsy. Data was collected from seven families, between March and April 2009, through semi-structured interviews. The analysis followed the principles of thematic interpretation. The difficulties are more evident than the abilities and bring repercussions to daily life activities. Dealing with difficulties to control seizures, spasticity, changes in postural tone, occurrence of primitive reflexes, result in the complexity to perform simple tasks like feeding, bathing, locomotion, because children become increasingly dependent on caregivers. Over time, the difficulties give way to the routine and adaptation to the child's daily life. Strengthening relationships with families by improving their bonds and developing quality and comprehensive actions, promotes the welfare of the family / child with cerebral palsy.

Descriptors: Cerebral palsy. Family. Child care.

Title: Family's abilities and difficulties in caring for children with cerebral palsy.

a Fisioterapeuta. Mestre em Enfermagem. Docente do Centro Universitário de João Pessoa-UNIPÊ, João Pessoa-Paraíba. Brasil.

b Fisioterapeuta. Doutora em Psicologia Escolar e do Desenvolvimento Humano. Docente do Curso de Graduação em Fisioterapia da Universidade Federal do Rio Grande do Norte. Natal-Rio Grande do Norte. Brasil.

c Enfermeiro da Estratégia Saúde da Família de Salgado de São Félix-Paraíba. Mestre em Enfermagem. Docente do Curso de Graduação em Enfermagem do Instituto Paraibano de Educação. João Pessoa-Paraíba. Brasil.

d Enfermeira. Doutora em Enfermagem. Docente do Curso de Graduação e do Programa de Pós-Graduação em Enfermagem da Universidade Federal da Paraíba. João Pessoa-Paraíba. Brasil. 


\section{INTRODUÇÃO}

Doença crônica é definida como uma condição que afeta as funções do indivíduo em suas atividades diárias por mais de três meses, podendo causar hospitalização. Geralmente, são incuráveis, deixam sequelas, impõem limitações de funções ao indivíduo, envolvem os desvios da fisiologia normal e requerem treinamento especial para sua reabilitação ${ }^{(1)}$. A condição crônica na infância interfere no funcionamento do corpo da criança em longo prazo, requer assistência e seguimento por profissionais de saúde, limita as atividades diárias, causa repercussões no seu processo de crescimento e de desenvolvimento, afetando o cotidiano de todos os membros da família ${ }^{(2)}$.

A criança com PC necessita de um cuidado diferenciado, pois apresenta limitações no desempenho de suas atividades de vida diária, como autocuidado, higiene, interação social, necessitando de ajuda de cuidadores ${ }^{(3)}$. Assim, é importante o acompanhamento e a orientação de uma equipe multiprofissional que possibilite a compreensão do processo terapêutico para participar com segurança do enfrentamento do diagnóstico e do processo de tomada de decisões em relação às condutas terapêuticas para um desenvolvimento neuropsicomotor satisfatório.

São várias as doenças crônicas da infância, mas, nesta pesquisa, incidiremos sobre a paralisia cerebral (PC), tendo em vista ser uma doença que denota incapacidades e diferentes tipos de dependência, refletindo no meio familiar e necessitando de maior adaptação por parte dos que convivem com a criança.

A PC tem implicações para o desenvolvimento da criança e de seu convívio familiar. Pesquisas ${ }^{(4-5)}$ identificaram que a família de crianças com PC sempre espera o nascimento de um filho saudável e, ao receber um diagnóstico dessa natureza, vários processos são desencadeados, perpassando pelas fases de luto, de choque, de negação, de aceitação e de adaptação. Em sua dinâmica cotidiana, a família buscará formas para se readaptar e enfrentar essa nova situação, a fim de resgatar o bem-estar de todos. Este não é um processo fácil, mas, com o tempo, todos passam a aceitar e se adaptam às novas exigências.

Esse processo de adaptação, em geral, desencadeia vulnerabilidades no contexto familiar.
Pesquisa ${ }^{(6)}$ sobre vulnerabilidade socioeconômica no cenário de assistência de enfermagem pediátrica enfatiza a "necessidade de um conhecimento do contexto de vida de um indivíduo para que se entenda que a concepção de vulnerabilidade modifica de pessoa para pessoa, determinada por diversos fatores, entre eles, a capacidade de enfrentamento das dificuldades, sejam elas de que ordens forem".

Nesse processo, o profissional deve estabelecer uma relação próxima e contínua com a família, resgatando a essência do cuidado integral para enxergar as necessidades do outro, levando em consideração aspectos sociais, culturais, afetivos. $\mathrm{O}$ foco desse modo de produzir o cuidado não está centrado apenas no biológico, mas amplia para a escuta sensível e o diálogo reflexivo. Assim, é importante que a equipe de saúde e a família construam juntas uma proposta terapêutica, apreendendo a criança para além da sua deficiência, tendo, como fio norteador, o cuidado ampliado multidisciplinar.

$\mathrm{Na}$ vivência profissional e no convívio com famílias de crianças com paralisia cerebral, foi possível observar que essa doença apresenta um prognóstico obscuro, traduzindo-se em limitações nas atividades de vida diária e dependência, na maioria dos casos. Muitas famílias explicitam dificuldades para cuidar da criança. Assim, necessitam de um suporte ampliado e de trabalho em grupos de famílias para troca de experiências, buscando fortalecer as potencialidades das famílias no cuidado à criança por meio do apoio que cada membro proporciona ao outro. Ações dessa natureza contribuem para o processo de reestruturação da dinâmica familiar, resgatando o bem-estar de todos.

A partir do exposto, foi traçado o seguinte questionamento: quais fatores dificultam e/ou facilitam o envolvimento da família no acompanhamento da criança com PC? Para tanto, esta pesquisa teve como objetivo apreender as facilidades e as dificuldades da família no cuidado às crianças com PC.

Este estudo pode proporcionar contribuições para a área da saúde, sobretudo a enfermagem, demonstrando a importância de uma equipe multiprofissional na assistência às crianças com Paralisia Cerebral e evocando a importância do envolvimento da família neste contexto. Nesse sentido, esta pesquisa poderá subsidiar ações futuras para a melhoria do apoio prestado à família, no sentido de melhorar o vínculo e a relação entre equipe de saúde e família/criança. 


\section{METODOLOGIA}

Pesquisa de abordagem qualitativa do tipo exploratório-descritiva realizada no domicílio dos familiares de crianças atendidas na Clínica Escola de Fisioterapia de um Centro Universitário do município de João Pessoa- PB. Os sujeitos da pesquisa foram sete familiares de crianças com $\mathrm{PC}$, selecionados aleatoriamente entre os meses de março e de abril de 2009, de acordo com os seguintes critérios de inclusão: ser familiar e/ ou responsável pela criança com PC; que essas crianças fossem atendidas há mais de seis meses na clínica em estudo. A técnica de coleta de dados foi a entrevista semiestruturada, que foi gravada após autorização dos sujeitos, a fim de captar o contex to do cuidado à criança.

O critério de encerramento da coleta foi o de saturação e os dados foram analisados a partir dos princípios da interpretação temática ${ }^{(7)}$, de acordo com os seguintes passos: ordenação, classificação e análise final. A partir da transcrição das entrevistas, procedeu-se à leitura exaustiva do material, a fim de organizar os depoimentos em determinada ordem. Posteriormente, foram reagrupados os temas encontrados, a fim de construir as estruturas de relevância para a análise final. Atendendo aos preceitos da Resolução Nº 196/96 do Conselho Nacional de Saúde, o projeto foi submetido ao Comitê de Ética da universidade a qual a clínica em estudo está vinculada, tendo sido aprovado sob o protocolo

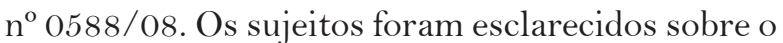
objetivo do estudo, assegurando-lhes o direito a não participar da pesquisa, ao anonimato, inclusive, na divulgação da mesma. Todos assinaram o Termo de Consentimento Livre e Esclarecido.

\section{RESULTADOS E DISCUSSÃO}

As famílias relatam facilidades e dificuldades no cuidado diário ao filho com PC. Contudo, observou-se que, enquanto as crianças são pequenas, as facilidades no cuidado e as formas de adaptações ergonômicas, como cadeiras, banheiras são mais acessíveis. Porém, quando as crianças crescem, as dificuldades aumentam, pois o mercado não oferece materiais adaptados e muitos desses equipamentos apresentam custo elevado, sendo difícil a acessibilidade. Algumas mães relataram não apresentar dificuldades em dar o banho, na alimentação e no repouso da criança.
Ela dorme na cama sozinha. Hoje em dia não, ela mesma vira para dormir, pois não virava antes, não precisa mais de grade, ela não faz mais xixi e nem coco na roupa, ela pede e a gente leva para o banheiro (E2).

Ele não fica em pé ainda, eu encho a banheira e coloco ele dentro. Não acho ruim [...] Eu dou a mamadeira. Quando ele chega em casa come verduras. Eu passo no liquidificador e ele come bem de colher (E5).

Diferentes modos de comunicação da família com a criança vão sendo construídos no processo de cuidado, tornando-se um facilitador para apreender e para atender as necessidades da criança com PC.

Se a gente demorar muito ela cai no choro. O choro quer dizer que ela não está gostando de ficar só. Quando ela quer uma coisa ou vocêfaz o que ela quer, ou se prepare para o choro até conseguir (E1).

A gente já sabe que ela não quer mais ficar deitada porque chora. A gente tira ela da cama e leva para a sala, ela quer escutar música. Ela chora muito quando não gosta de algo ou está abusada (E4).

Tudo que a gente pergunta ele responde do jeito dele. Quando acorda dá sinal, grita para sair, chamando alguém. Aí tem que ser o que ele quer, o desenho que ele quer porque se não chora, grita. Essas crianças são cheias de gosto (E7).

O processo de comunicação estabelecido por códigos, por símbolos e por uma linguagem própria identifica vínculos no grupo social e gera efeitos positivos entre seus membros ${ }^{(1)}$. A família vai descobrindo a melhor maneira de interagir com o filho para compreender suas necessidades.

À medida que a criança cresce, as atividades de vida diária tornam-se mais difíceis e observa-se atrasos no seu desenvolvimento, aquisição de posturas inadequadas, movimentos exacerbados. A partir desse momento, a família vivencia as dificuldades que se tornarão mais pronunciadas com o crescimento físico da criança, mas sem o acompanhamento do desenvolvimento neuropsicomotor.

É tudo difícil, não tem nada fácil [...] se cuidar de um filho normal é difícil, imagina um filho especial (E6).

Uma das principais dificuldades relatadas pelas mães é a influência das repercussões da doença nas atividades de vida diária. A espasticidade que dificulta os movimentos da criança, a hipotonia que não 
permite a fixação de algumas posturas e as crises convulsivas e de difícil controle são algumas das manifestações clínicas em crianças com PC e que dificultam o cuidado no domicílio.

Na hora de arrumar é um problema. A gente pede para ela ajudar e o cérebro não aceita, quando a gente pede para ela fazer assim no braço, o braço faz assim (demonstrou), é sempre o contrário. A gente nota que ela quer ajudar, está entendendo, mas não ajuda porque vai pegar e o braço fica duro (E2).

E ele é muito impaciente, tem uns movimentos que se a gente não tiver cuidado ele cai do braço (E7).

Estudo $^{(8)}$ identificou que, para as mães de crianças com PC, a doença é um obstáculo a mais a ser superado no cotidiano com seus filhos. Devido à espasticidade ${ }^{(9)}$, a reabilitação pode amenizar as dificuldades, pois, mesmo a PC não sendo progressiva, o quadro motor e funcional pode se modificar com o crescimento. Portanto, não se pode apenas tratar as alterações musculares; o foco está em trabalhar essas crianças, tentando melhorar a sua qualidade de vida, pois "alguma melhora é uma grande melhora”.

Com o passar do tempo e o crescimento das crianças, as dificuldades vão se tornando mais pronunciadas. Atividades que, antes, eram ditas fáceis de realizar, como dar banho em uma banheira, tornam-se difíceis, assim como vestir a roupa e dar a alimentação no colo.

Está ficando difícil porque ele está crescendo e a banheira ficando pequena. Ele tem muitos espasmos, joga a água para todo lado. [...] tem que comer comida pastosa porque não mastiga a comida, engasga. Para dar a comida, às vezes, ele fica irritado e cospe a comida, leva muito a mão à boca, trava, fica difícil (E3).

Escovo os dentes dele, mas não é tão fácil porque ele não sabe cuspir, tenho que colocar pouca pasta na escova para ele não engolir, ele não sabe jogar a pasta fora [...] O banho é na cadeira de balanço, mas é ruim porque ele é muito grande e pesado (E7).

Os pacientes com comprometimento neurológico dependem de um cuidador que, geralmente, é alguém da família, para realizar atividades consideradas banais. Essas atividades, como tomar banho, caminhar, são acompanhadas de dificuldade ${ }^{(10)}$. Cuidar de uma criança com o que se denomina padrão de crescimento e de desenvolvimento "normal" é uma tarefa complexa e que necessita de tempo, e se a criança, por algum motivo, apresenta uma lesão cerebral com consequências motoras, o cuidar se torna mais difícil, devido às alterações clínicas da disfunção, como atraso no desenvolvimento neuropsicomotor, distúrbios de movimento, linguagem, cognitivo etc.

A atividade considerada pelos entrevistados como sendo a mais difícil foi a locomoção. Com o crescimento da criança, as alterações clínicas se exacerbam, dificultando o cuidado, sobretudo na locomoção, pois o desenvolvimento neuropsicomotor está comprometido.

Como ainda ela não consegue ficar de pé e sentar normal, a locomoção torna-se um pouco difícil, mas a gente tem o carrinho de bebê que usamos para passear (E1).

Até semana passada eu levava ele nos braços, mas como já está com 4 anos está muito pesado, dificulta muito (E3).

[...] tem a dificuldade para sair de casa porque para sair com ele tem de ser de carro e eu para pegar o ônibus tenho que levar ele nos braços e pesa muito (E5).

Embora as dificuldades estejam presentes e sejam mais evidenciadas pelas mudanças ${ }^{(11)}$ que desencadeiam no cotidiano da família, com o passar do tempo, cedem lugar para a rotina e para a adaptação à vida da criança.

Já foi mais difícil [...] com o passar do tempo a gente vai se acostumando [...] mas eu acho que a gente não acha mais nem tanta dificuldade pelo tempo, a convivência do dia a dia, a gente se acostuma (E2).

Diante da natureza dependente da criança portadora de deficiência e suas necessidades especiais, os pais experimentam momentos de insegurança e, frente a novas experiências, poderão agir, inicialmente, de maneira ineficaz ${ }^{(12)}$. Porém, com o passar do tempo, as tarefas tornar-se-ão mais simples e a rotina consumirá menos tempo, pois ocorre a adaptação e a adequação à nova situação.

A falta de infraestrutura das cidades e domiciliar é outro problema enfrentado pela família e que dificulta o cuidado à criança com $\mathrm{PC}$, pois, como a família não espera o nascimento de um membro com deficiência, o lar segue as estruturas padronizadas, ficando difícil a adaptação da criança com deficiência. 
A locomoção. As ruas não ajudam, o calçamento é horrível [...] no braço direto ninguém aguenta ficar com ela. [… É difícil, mas é assim (E2).

Minha casa é cheia de batente. Para sair para rua é um batente enorme, e nessa rampa dá medo de a cadeira descer com tudo e $V$. (criança) ir junto (E2).

Tem dificuldade porque tem muito buraco na rua e a gente atravessa um campo de futebol que tem uns batentes altos e também para descer na rua tem o meio-fio (E7).

Essas famílias se deparam com municípios onde a infraestrutura urbana não foi projetada para pessoas que necessitam de auxílio para a locomoção(13). Essas dificuldades relativas ao cuidado da criança com PC no cotidiano desencadeiam estresse à família.

É difícil. A gente convive com o problema, tem experiência, mas não sabe resolver. Quando ela está estressada grita o tempo inteiro, atrapalha o irmão, atrapalha o trabalho do pai [...] é ruim porque ela estressa, vomita, fica nervosa e a gente não sabe o que fazer [...] você quer estudar, seu marido trabalhar. É estresse para todos (E6).

O desgaste físico e emocional está presente no cotidiano dessas famílias, havendo a necessidade de os pais e/ou cuidadores também serem cuidados. Se esses cuidadores não tiverem tempo para realizar atividades que melhorem seu bem-estar, começarão a ter problemas que dificultarão o cuidado aos seus filhos pelo estresse físico e emocional, gerado pela sobrecarga no cuidado.

$\mathrm{Na}$ rotina diária, o cuidador vivencia diversas situações na família, como escassez de recursos financeiros, exercício de múltiplos papéis na família, sentimentos de desamparo, perda de controle, exclusão e sobrecarga. Isto pode gerar estresse ao cuidador como resposta às exigências fundamentais ${ }^{(14)}$. Estu$\mathrm{do}^{(15)}$ enfatiza que o estresse da família cuidadora da criança está relacionado com os níveis de suporte social percepcionado pelos mesmos. Neste estudo, as famílias exemplificam o apoio social pela ajuda recebida de outras pessoas no cuidado ao filho. Em geral, esse apoio ocorre entre os membros da família extensiva.

Na minha família eu tenho muita ajuda da minha mãe. Eu digo sempre ao meu esposo: se eu não tivesse a minha mãe eu não deixaria a S. com ninguém. Não é questão de não confiar é porque se para a mãe é difícil de cuidar de uma criança especial, imagine para quem não é mãe? (E1).
Tem minha sogra que me ajuda. Se não fosse ela é que era difícil mesmo (E5).

Tem uma irmã minha que ajuda 3 dias com $G$. (criança) e meu filho ajuda quando está em casa e tem tempo (E7).

O suporte social abrange a rede que o cuidador tem para o processo de cuidar no domicílio. Inclui o suporte oferecido pela família ou outras pessoas que se dispõem a ajudar, a organização de serviços que proporcionam assistência ao indivíduo, o amparo social, educativo, espiritual e de saúde ${ }^{(16)}$. O suporte social é um importante fator de minimização dos efeitos das situações estressantes na dinâmica familiar, contribuindo para as adaptações às situações de estresse.

A mãe é o cuidador primário das crianças com PC, e o cuidar da criança é uma tarefa culturalmente delegada à mulher. Dentre outras pessoas que ajudam no cuidado, destacamos a avó, principalmente a materna, e os pais da criança, quando não estão em horário de trabalho, com cuidados auxiliares. Fechando a teia da rede de apoio social encontrada nesta pesquisa, salientamos a presença da Igreja, representada pelos fiéis, que ajudam com auxílio de transporte ou apoio financeiro.

Tem um irmão na igreja que pergunta se $V$. (criança) vai para igreja. Ele tem uma caminhonete e passa aqui para pegar a gente e depois vem deixar (E2).

Ele fica numa cadeira de rodas, que foi o pastor que deu. Ele fez uma campanha lá na igreja para a gente comprar essa cadeira (E7).

As redes sociais que for necem apoio à família são importantes na ajuda do cuidado à criança com PC. Reforçar esse apoio social é fundamental, pois é um forte aliado da família e da criança na superação das dificuldades que surgem no desenvolvimento e no crescimento infantil com uma disfunção neurológica.

O apoio social pode advir da troca de experiências entre famílias por meio de dinâmica de grupos. Neste estudo, todas as mães foram enfáticas em demonstrar o desejo em participar de atividades dessa natureza e da importância disso para a superação em conjunto de problemas vivenciados no cotidiano.

O grupo de mães é bom para dividirmos as experiências, para ficarmos mais tranquilas com as experiências das outras (E2). 
Eu tive ajuda de outras mães. Vi que não era só eu que tinha G. especial. A gente foi trocando ideias o que as outras mães passaram o que eu passei e cada uma vai conversando e isso vai ajudando, $[\ldots]$ porque quando a gente fica sozinha pensando no problema, fica pior e o problema se torna maior. A gente dividindo com pessoas que têm o mesmo problema, torna-se mais fácil (E3).

É de vital importância que os profissionais de saúde busquem se capacitar para lançar mão de técnicas que possibilitem o fortalecimento das relações humanas, pois, quando o foco da atenção é a doença, a produção de cuidados fica comprometida e atende a uma racionalidade que submete as crianças doentes cronicamente e seus familiares à normas e à rotinas rígidas, em detrimento de suas necessidades particulares ${ }^{(17)}$. Novas estratégias para o trabalho em saúde são necessárias para o desenvolvimento de ações mais efetivas e eficazes em relação aos objetivos propostos. As atividades em grupo $^{(18)}$ podem ser uma das estratégias a ser utilizada para melhorar a qualidade da assistência.

O espaço criado para as discussões em grupo de famílias com os mesmos problemas possibilita a troca de experiências e permite que as famílias falem de suas angústias e de suas expectativas. Essa estratégia procura mostrar aos pais a importância de sua participação ativa no processo de desenvolvimento da criança, dando-lhes suporte informativo e emocional. Estudo ${ }^{(19)}$ demonstra a necessidade de melhorar a comunicação, a participação, a aceitação e a motivação da criança na atenção a sua saúde, a fim de manter a individualidade, diminuir o estresse e possibilitar a implementação de um cuidado atraumático à criança e a sua família. Ações dessa natureza remetem à necessidade de reorganização do processo de trabalho para a construção da perspectiva da integralidade do cuidado.

Atividades em grupo demonstram sua relevância, pois os depoimentos revelam a extrema preocupação com a criança com deficiência em detrimento do cuidado de si. Salientamos que o familiar envolvido no processo necessita de cuidados e de apoio para que possa enfrentar a rotina e o estresse gerado pelos cuidados contínuos e permanentes com a criança com PC.

Outra dificuldade enfrentada pelas famílias de crianças com PC é o processo de inclusão escolar. Vários decretos vêm sendo elaborados no Brasil e no mundo para garantir esses direitos. No entanto, faltam condições que garantam, não somente $o$ acesso às escolas, mas a permanência e o sucesso desses alunos matriculados em classes comuns, com profissionais especializados e aptos a atender as necessidades dessas crianças.

A intenção da maioria das mães é de colocar seus filhos na escola, algumas já tinham ou estavam em experiência, mas a unanimidade evidenciou que as escolas recebem a criança, pois está na lei e elas são obrigadas, mas não fazem um trabalho diferenciado com as mesmas.

\begin{abstract}
A professora pega na mão dele para pintar, só que não éo ideal para ele, eu sei. A TO (terapeuta ocupacional) falou que tem que fazer coisas que chame a atenção dele [...] com barulhos [...] e lá elas passam uma tarefa igual às outras crianças. Tem vez que ela puxa a mão para ele pintar, mas ele não gosta [...] eu conversei com elas para ver um jeito diferente para ele. Eu fiquei de conversar com uma colega e ver o que poderia ser feito. Ela falou que tem cursos que as professoras podem participar a fim de aprender a tratar de crianças especiais [...] eu sei que tem de ter uma tarefa diferente, que chame mais a atenção dele (E5).
\end{abstract}

Os cuidadores ${ }^{(20)}$ elencam dificuldades relativas ao despreparo da escola para inclusão da criança com PC: falta de capacitação dos professores; despreparo geral para lidar com a criança; falta de estagiário de apoio; falta de materiais e de equipamentos adaptados; falta de acessibilidade física; desinteresse e medo/insegurança do professor em ensinar; comportamento superprotetor e preconceito por parte deles, além das dificuldades da criança inerentes a sua condição física, como: falta de coordenação motora/dependência; dificuldades no aprendizado; faltas frequentes; problemas emocionais/comportamento; limitação para as atividades físicas; falta de equipamento adaptado (carteiras); dificuldade em separar-se da mãe; gravidade do quadro clínico.

É importante destacar que essas dificuldades não devem ser impeditivas para a criança frequentar a escola regular. Por isso, é de fundamental importância que tenhamos escolas inclusivas, com profissionais habilitados, tanto do ponto de vista pedagógico, quanto de equipamentos e de acessibilidade.

\section{CONSIDERAÇÕES FINAIS}

As crianças com PC dependem, em geral, integralmente de outra pessoa para realizarem suas atividades diárias e necessitam de um suporte terapêutico de reabilitação contínuo. Essa condição faz com que a presença do cuidador torne-se vital para a manutenção do seu bem-estar. 
Quando o filho é ainda bebê, as mães têm facilidade para cuidar, porém, com o crescimento da criança, as atividades tornam-se difíceis, tanto pelo curso da doença, quanto pelo aumento da estatura e do peso. No cuidado à criança com $\mathrm{PC}$, as famílias relataram que as dificuldades são mais proeminentes que as facilidades. As maiores dificuldades encontradas neste estudo foram as repercussões da doença nas atividades de vida diária, como convulsões de difícil controle, espasticidade, alterações de tônus postural, presença de reflexos primitivos. Assim, atividades ditas fáceis, como alimentar, dar banho, locomover, tornam-se difíceis e a criança fica, a cada dia, mais dependente dos seus cuidadores. Com o passar do tempo, as dificuldades sedem lugar à rotina e à adaptação.

A mãe, cuidadora primária, que antes se responsabilizava pelo funcionamento e pela dinâmica familiar como um todo, muda seu foco de cuidado, centralizando-o no filho com PC. Ela conta com a ajuda de outros membros da família, principalmente do pai, da avó materna e dos outros filhos. Com inúmeras dificuldades, esses cuidadores vivem situações de estresse, mas com o apoio social de amigos, membros da família nuclear, extensiva e de outras famílias de crianças com PC, fortalecem o vínculo, amparando a todos no processo de enfrentamento.

A equipe interdisciplinar, articulada com a família, pode promover uma nova lógica no trabalho da equipe de saúde, permitindo o cuidar na perspectiva da integralidade, de maneira que os profissionais passem a perceber os familiares como agentes envolvidos no processo, valorizando sua autonomia, seus sentimentos e suas necessidades.

É imprescindível que o acompanhamento da criança com PC tenha suas diretrizes revistas em cada situação singular de atendimento e de seu contexto familiar. Cabe aos profissionais envolvidos no processo estreitar as relações com a família, melhorando o vínculo e desenvolvendo ações de qualidade e integrais. Estudos futuros dessa temática poderão contribuir para a reflexão acerca do cuidado à criança com PC e sua família.

\section{REFERÊNCIAS}

1 Silva FM, Correa I. Doença crônica na infância: vivencia do familiar na hospitalização da criança. Reme: Rev Mineira Enferm. 2006;10(1):18-23.

2 Ribeiro RLR, Rocha SMM. Enfermagem e famílias de crianças com síndrome nefrótica: novos elementos e horizontes para o cuidado. Texto Contexto Enferm. 2007;16(1):112-9.

3 Camargos ACR, Lacerda TTB, Viana SO, Pinto LRA, Fonseca LMS. Avaliação da sobrecarga do cuidador de crianças com paralisia cerebral através da escala Burden Interview. Rev Bras Saúde Mater Infant. 2009;9(1):31-7.

4 Dantas MAS. Participação da família no cuidado a criança com paralisia cerebral. [dissertação]. João Pessoa. Programa de Pós-Graduação em Enfermagem, Universidade Federal da Paraíba; 2009.

5 Dantas MSA, Collet N, Moura FM, Torquato IMB. Impacto do diagnóstico de paralisia cerebral para a família. Texto Contexto Enferm. 2010;19(2):229-37.

6 Pedroso MLR, Motta MGC. A compreensão das vulnerabilidades sócio-econômicas no cenário da assistência de enfermagem pediátrica. Rev Gaúcha Enferm. 2010;31(2):218-24.

7 Minayo MCS. Desafio do conhecimento: pesquisa qualitativa em saúde. $11^{\text {a }}$ ed. São Paulo: Hucitec-Abrasco; 2009.

8 Vieira NGB, Mendes NC, Frota LMCP, Frota MA. O cotidiano de mães com crianças portadoras de paralisia cerebral. Rev Bras Promoção Saúde. 2008;21(1):55-60.

9 Leite LMGC, Souza Júnior SLP, Bier A. Reabilitação física e psicossocial na paralisia cerebral através da arte-terapia: relato de caso. Rev Digital Buenos Aires. 2009;14(132).

10 Bim CR, Carvalho MDB, Peloso SM. Fisioterapia no enfrentamento de perdas em pacientes com doenças neurológicas. Rev Fisiot Movim. 2007;20(3):71-8.

11 Milbrath VM, Cecagno D, Soares DC, Amestoy SC, Siqueira HCH. Ser mulher mãe de uma criança portadora de paralisia cerebral. Acta Paul Enferm. 2008;21(3):427-31.

12 Lima RABC. Envolvimento materno no tratamento fisioterapêutico de crianças portadoras de deficiência: compreendendo dificuldades e facilitadores [dissertação]. Belo Horizonte: Faculdade de Medicina, Universidade Federal de Minas Gerais; 2006.

13 Milbrath VM. Cuidado da família à criança portadora de paralisia cerebral nos três primeiros anos de vida [dissertação]. Rio Grande: Universidade Federal do Rio Grande; 2008. 
14. Oliveira MFS, Silva MBM, Frota MA, Pinto JMS, Frota LMCP, SÁ FE. Qualidade de vida do cuidador de crianças com paralisia cerebral. Rev Brás Promoção da Saúde. 2008;2 1(4):275-80.

15 Almeida T.; Sampaio FM. Stresse e suporte social em familiares de pessoas com paralisia cerebral. Rev Psic Saúd Doenças. 2007;8(1):145-151.

16 Morais AC, Quirino MD, Almeida MS. O cuidado da criança prematura no domicílio. Rev Acta Paul Enferm. 2009;22(1):24-30.

17 Silva JB, Kirschbaum DIR, Oliveira I. Significado atribuído pelo enfermeiro ao cuidado prestado à criança doente crônica hospitalizada acompanhada de familiar. Rev Gaúcha Enferm. 2007;28(2):250-9.
18 Andraus LMS, Oliveira LMAC, Minamisava R, Munari DB, Borges IK. Ensinando e aprendendo: uma experiência com grupos de pais de crianças hospitalizadas. Rev Eletr Enferm [Internet]. 2004 [citado 2010 ago 20].06(1):98-103. Disponível em: http://www.fen.ufg.br/revista/revista6_1/pdf/ r2_pais.pdf

19 Jansen MF, Santos RM, Favero L. Benefícios da utilização do brinquedo durante o cuidado de enfermagem prestado à criança hospitalizada. Rev Gaúcha Enferm. 2010;31(2):247-53.

20 Silva RVGO. Ramos FRS. O trabalho de enfermagem na alta de crianças hospitalizadas: articulação da atenção hospitalar e básica. Rev Gaúcha Enferm. 2011;32(2):309-15.

\author{
Endereço da autora / Dirección del autor / \\ Author's address \\ Neusa Collet \\ Caixa Postal, 141, Intermares \\ 58310-000, Cabedelo, PB \\ E-mail:neucollet@gmail.com
}

Recebido em: 10.08.2011

Aprovado em: 31.08 .2012 